Hydrol. Earth Syst. Sci., 13, 2191-2201, 2009

www.hydrol-earth-syst-sci.net/13/2191/2009/

(C) Author(s) 2009. This work is distributed under

the Creative Commons Attribution 3.0 License.

\title{
Surface water acidification and critical loads: exploring the F-factor
}

\author{
L. Rapp and K. Bishop \\ Department of Aquatic Sciences and Assessment, Swedish University of Agricultural Sciences, 75007 Uppsala, Sweden
}

Received: 26 April 2009 - Published in Hydrol. Earth Syst. Sci. Discuss.: 26 May 2009

Revised: 11 October 2009 - Accepted: 1 November 2009 - Published: 17 November 2009

\begin{abstract}
As acid deposition decreases, uncertainties in methods for calculating critical loads become more important when judgements have to be made about whether or not further emission reductions are needed. An important aspect of one type of model that has been used to calculate surface water critical loads is the empirical F-factor which estimates the degree to which acid deposition is neutralised before it reaches a lake at any particular point in time relative to the pre-industrial, steady-state water chemistry conditions.

In this paper we will examine how well the empirical Ffunctions are able to estimate pre-industrial lake chemistry as lake chemistry changes during different phases of acidification and recovery. To accomplish this, we use the dynamic, process-oriented biogeochemical model SAFE to generate a plausible time series of annual runoff chemistry for ca. 140 Swedish catchments between 1800 and 2100. These annual hydrochemistry data are then used to generate empirical Ffactors that are compared to the "actual" F-factor seen in the SAFE data for each lake and year in the time series. The dynamics of the F-factor as catchments acidify, and then recover are not widely recognised.

Our results suggest that the F-factor approach worked best during the acidification phase when soil processes buffer incoming acidity. However, the empirical functions for estimating $\mathrm{F}$ from contemporary lake chemistry are not well suited to the recovery phase when the F-factor turns negative due to recovery processes in the soil. This happens when acid deposition has depleted the soil store of $\mathrm{BC}$, and then acid deposition declines, reducing the leaching of base cations to levels below those in the pre-industrial era. An estimate of critical load from water chemistry during recovery and empirical $\mathrm{F}$ functions would therefore result in critical loads that are too low. Therefore, the empirical estimates of
\end{abstract}

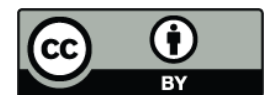

Correspondence to: L. Rapp

(lars.rapp@ vatten.slu.se) the F-factor are a significant source of uncertainty in the estimate of surface water critical loads and related calculations for quantifying lake acidification status, especially now that acid deposition has declined across large areas of Europe and North America.

\section{Introduction}

The critical load concept (CL) has become the basis for reducing the acidifying air pollution in Europe, where the $\mathrm{CL}$ is defined as "a quantitative estimate of an exposure to one or more pollutants below which significant harmful effects on specified elements of the environment do not occur according to present knowledge" (Nilsson and Grennfelt, 1988). The concept has proved successful as a basis for the European co-operation on emission reductions within the framework of the UNECE CLRTAP. For large areas of Scandinavia, acid deposition is now declining towards the critical load (Hettelingh et al., 2008). It is estimated that the percentage of Swedish lakes where critical loads are exceeded has decreased from $62 \%$ in 1980 to $19 \%$ in 2002 2004. The full implementation of the Gothenburg protocol (UNECE, 1999), signed in 1999, will further reduce the exceedances to about 12\% of Swedish lakes in 2020 (SEPA, 2007). When exceedances approach zero, the uncertainties in data and methodologies for calculating critical load become more important as judgements have to be made of the extent to which further emission reductions are needed. These developments call for a careful assessment of the methods for calculating critical loads and exceedances.

A key component of the model for calculating critical loads of acidity for surface waters that was used in Scandinavia, among other countries, and recently has been applied in the US, Canada and other parts of Europe, is the F-factor in the Steady State Water Chemistry model (Henriksen et al., 1992; Dupont et al., 2005; Watmough et al., 2005; Curtis et

Published by Copernicus Publications on behalf of the European Geosciences Union. 
al., 2005). This paper examines the theory and features of that F-factor. Time series from a regional application of a process-oriented, dynamic hydrogeochemical model, SAFE (Warfvinge and Sverdrup, 1992a) are used to predict runoff chemistry from Swedish soils between 1800 and 2100. The corresponding F-factors are calculated and compared to the F-factors estimated from the empirical equations used in critical load calculations. This enables us to examine the ability of these empirical functions to reproduce the dynamics of the F-factor during the acidification- and the recovery phase, as well as the implications of these findings for critical loads.

\subsection{Background}

Acidification of surface waters is driven to a large extent by soil acidification. This is a process that involves a change in a number of catchment parameters, such as soil base saturation and $\mathrm{pH}$, alkalinity and the ANC (Acid Neutralising Capacity) of soil water. Changes in soil acidity, as measured in base saturation, indicate soil acidification but not necessarily lake acidification. Theoretically, if a large change in base saturation of the catchment soil has occurred due to a large input of strong acid, the alkalinity and ANC of the lake may not have changed to nearly the same extent. This has to do with the dynamics of acidification; soils are, to some extent, capable of neutralising strong acids and thus undergo acidification, which is not immediately expressed in lake $\mathrm{pH}$ or ANC. At some point, however, the buffering capacity of the soil can decline to the point where the input of acids to the soils results in lake acidification.

If it can be assumed that sulphur (S) is not significantly retained in the catchment, the relative change in the lake concentrations of base cations and sulphate provide information about the extent to which the lake is undergoing acidification, and the extent to which lake acidification is buffered by the catchment soils. If, for example, the base cations and sulphate in runoff increase to about the same extent as acid deposition increases, then only the soil is acidifying. On the other hand, a larger increase in the concentration of sulphate than in base cations would indicate that the lake is undergoing acidification. This is the basis of the F-factor, which is a key feature in some empirical models for evaluating the degree of acidification and calculating critical loads of acidity for surface waters.

The F-factor was introduced by Henriksen $(1982,1984)$. The interplay between soil and water acidification was recognised earlier, however, e.g. in Henriksen (1979) and Dickson (1980). The latter study raised the question of whether or not the soil buffering processes could be reflected in the properties of the acidified waters, i.e. is it possible to "see" soil acidification in lake water? During the 1990's when several important CLRTAP protocols were developed, the F-factor was widely used, in particular for calculating surface water critical loads (Henriksen et al., 1992, 1993; Posch et al., 1997). All countries delivering data on surface water critical loads to the European Effects Programme of the UN/ECE Convention on Long Range Transboundary Air Pollution have used methods that include the F-factor in some respect (Posch et al., 1999). Dynamic models are now more widely used (Hettelingh et al., 2008) but applications of the F-factor based models continue in Europe, North America, and Canada (Curtis et al., 2005; Dupont et al., 2005; Watmough et al., 2005).

\subsection{What does the F-factor tell us?}

The F-factor is defined as the change in the concentration of base cations divided by the change in the concentration of sulphate at any particular point in time relative to the preindustrial, steady-state water chemistry conditions:

$\mathrm{F}=\frac{\left[\mathrm{BC}^{*}\right]_{t}-\left[\mathrm{BC}^{*}\right]_{o}}{\left[\mathrm{SO}_{4}^{*}\right]_{t}-\left[\mathrm{SO}_{4}^{*}\right]_{o}}$

where $\mathrm{F}$ is the $\mathrm{F}$-factor (dimensionless) and $\left[\mathrm{BC}^{*}\right]$ and $\left[\mathrm{SO}_{4}^{*}\right]$ are the concentrations of non-marine base cations and sulphate in a lake $\left(\mathrm{eq}^{-1}\right)$.

Present and pre-industrial time are indicated by " $t$ " and " $o$ ", respectively, and “*” denotes a non-marine component.

The $\left[\mathrm{BC}^{*}\right]_{o}$ is a term of great interest for critical loads because it reflects the weathering rate of the catchment, and thus the long-term capacity of the soils to sustainably neutralise acid deposition.

In order to solve for $\left[\mathrm{BC}^{*}\right]_{o}$, estimates of $\mathrm{F}$ and $\left[\mathrm{SO}_{4}^{*}\right]_{o}$, are needed. Different ways for estimating $\mathrm{F}$ can be found in the literature and are discussed in a later section. A review of how to estimate $\left[\mathrm{SO}_{4}^{*}\right]_{o}$ can be found in Wilander (1994a). In general, the equations for estimating $\left[\mathrm{SO}_{4}^{*}\right]_{o}$ rest on the assumption that $\left[\mathrm{SO}_{4}^{*}\right]_{o}$ is composed of two parts, one from background deposition, $\mathrm{A}$, and another one from weathering, linearly dependent on the concentration of $\mathrm{BC}$ in the lake:

$\left[\mathrm{SO}_{4}^{*}\right]_{o}=A+k \cdot\left[\mathrm{BC}^{*}\right]_{t}$

In this paper we assume that the effect of nitrogen $(\mathrm{N})$ is negligible. In pre-industrial time that assumption is probably well justified because of low nitrogen deposition. Even in present time, with higher nitrogen deposition, the nitrogen leaching is small from many Swedish catchments not affected by agriculture (Binkley and Högberg, 1997; Fölster, 2001). In other areas, for instance the UK and Italy, nitrate may be a major acid anion. However, nitrate acts in the same way as sulphur in the critical load models when it comes to the critical load of acidity (the acidifying effect of sulphur and nitrogen). Thus we can illustrate F-factor behaviour without reference to nitrogen.

The Steady State Water Chemistry model, SSWC, (Henriksen et al., 1990, 1992, 1993) assumes that the leaching of base cations at the present time is a result of deposition, weathering, nutrient uptake and ion exchange: 
$\mathrm{BC}_{t l e .}=\mathrm{BC}_{d}^{*}+\mathrm{BC}_{w}-\mathrm{BC}_{u}+\mathrm{BC}_{\Delta \mathrm{EX}}$

where $\mathrm{BC}_{t l e}$. is the non-marine leaching of base cations (eq ha $\left.{ }^{-1} \mathrm{yr}^{-1}\right), \mathrm{BC}_{d}^{*}$ is the non-marine deposition of base cations, $\mathrm{BC}_{w}$ is the catchment weathering rate, $\mathrm{BC}_{u}$ is the uptake of base cations that are removed by harvesting and $\mathrm{BC}_{\triangle \mathrm{EX}}$ is the net amount of base cations removed from the soil due to ion exchange reactions.

In pre-industrial times it is assumed that deposition and runoff chemistry (as reflected in lake chemistry) were in a steady state. Hence the net effect on ion exchange is zero (De Vries, 1991). Harvesting is considered negligible in pre-industrial times. Assuming that the non-marine deposition and weathering have not changed from pre-industrial to present times, we get the following mass balance defining the $\mathrm{BC}$ concentration in lake chemistry during pre-industrial times.

$\mathrm{BC}_{o}^{*}=\mathrm{BC}_{d}^{*}+\mathrm{BC}_{w}$

where $\mathrm{BC}_{o}^{*}$ is the non-marine pre-industrial leaching of base cations (eq $\mathrm{ha}^{-1} \mathrm{yr}^{-1}$ ). If the assumption of a stable deposition of base cations is not justified, then the difference in deposition between pre-industrial and present times has to be included in Eq. (5).

Combining Eqs. (3) and (4) shows that the numerator in Eq. (1), after being multiplied by runoff to yield a flux, is determined by ion exchange and net uptake of base cations:

$\mathrm{BC}_{t l e .}-\mathrm{BC}_{o}^{*}=-\mathrm{BC}_{u}+\mathrm{BC}_{\Delta \mathrm{EX}}$

Now the function of the F-factor can be clearly identified: the F-factor is a measure of the fraction of acidity from deposition of sulphur compounds presently reaching the lake that has been neutralised by ion exchange reactions in the catchment soil relative to pre-industrial times, taking into account any change in forest practices.

Another way of illustrating the function of the F-factor, neglecting nutrient uptake $\left(\mathrm{BC}_{u}\right)$, is to define soil acidification as $\mathrm{BC}_{\triangle \mathrm{EX}}$ and water acidification as $\mathrm{ANC}_{o}-\mathrm{ANC}_{t}$ (eq ha ${ }^{-1} \mathrm{yr}^{-1}$. If ANC is defined as:

$\mathrm{ANC}=\mathrm{BC}^{*}-\mathrm{SO}_{4}^{*} \quad($ pre - industrial and present times $)$

Then the F-factor can be expressed as:

$\mathrm{F}=\frac{\text { soil acidification }}{\text { water acidification }+ \text { soil acidification }}$

The expression of $\mathrm{F}$ suggests that the F-factor equals one when the lake is not acidifying and all acid deposition goes to acidifying the soil. The F-factor decreases as soil processes are progressively less capable of neutralising incoming acidity, which results in surface water acidification.

\subsection{Weathering from contemporary lake chemistry}

The immediate use of $\mathrm{F}$ for calculating critical loads and the acidification status of lakes is to estimate the pre-industrial base cation concentrations. As outlined by Eqs. (1) to (4), the approach is to proceed from the present concentration of $\mathrm{BC}$ and then quantify how much acid deposition and forestry have changed the concentration of BC in the lake (Eq. 5). The latter is taken care of by the F-factor, which estimates the quantity of base cations that are being leached out from the soils or are removed by harvesting. If estimates of $\mathrm{BC}_{\mathrm{dep}}^{*}$ are available, the weathering rate is given by Eq. (4).

As the calculations are based on present lake chemistry, the estimate of the weathering rate might be sensitive to short-term variation in water chemistry. Ideally, such a problem could be circumvented, if enough representative samples were available, by averaging chemistry over the course of several years (Wilander, 1994b).

In addition to the short-term variation in water chemistry due to varying weather conditions, there is also a long-term variation, associated with acidification and recovery. Naturally, it is difficult to separate short- and long-term variation, but by "long-term", we refer here to the variation caused by changing acid deposition and other human activities, and not a changing climate. In this case, the F-factor calculated at any particular time should be able to predict a stable steady state pre-industrial water chemistry, regardless of whether the sampled lakes are acidifying or recovering. Note that the F-factor changes as contemporary water chemistry changes in Eq. (1), given that $\left[\mathrm{BC}^{*}\right]_{o}$ and $\left[\mathrm{SO}^{*}\right]_{o}$ are constant.

An example of the influence on CL due to long-term changing lake chemistry can be found in (Watmough et al., 2005). CL was calculated, using SSWC, for 29 lakes using data collected 13 years apart. The authors concluded that the change in base cation concentration has had a substantial impact on the estimated CL.

In this paper, we will investigate this long-term variation in $\mathrm{F}$ in detail and see how well empirical F-functions capture the different phases, from pre-industrial chemistry, through acidification and recovery. To do this we will use the predictions of the SAFE model as a proxy for the development in the chemistry of about 140 Swedish lakes between 1800 and 2100. The use of the SAFE model does not provide us with the real truth, but is a good reflection of current knowledge of how soil chemistry controls runoff chemistry during acidification and recovery. The hydrochemical output from SAFE provides all the data needed to calculate both the "real" Ffactor for each year, and empirical estimates of the F-factor for that year. So even if SAFE does not give an absolutely correct estimate of lake chemistry, the discrepancies between the empirical F-factors and the SAFE prediction of F provide useful information about the internal consistency of the empirical F's, given a plausible time series of lake water chemistry. 


\section{Material and methods}

\subsection{Time series from the SAFE model}

SAFE (Warfvinge and Sverdrup, 1992a) is a dynamic, multilayer, soil chemistry model, developed with an emphasis on studying the effects of acid deposition on soils and groundwater. The SAFE model includes a number of processes among which cation exchange, chemical weathering and nutrient cycling of $\mathrm{BC}$ and $\mathrm{N}$ are the most important. Sulphate adsorption/desorption is, however, not included in the model version used in this paper. The inclusion of $\mathrm{S}$-adorption/desorption would delay the acidification phase and the recovery phase would take longer, but the key conclusions would be the same. The PROFILE model is the steady state version of SAFE and is used to calculate the initial steady state conditions. Additional descriptions of the model and their applications can be found in Warfvinge and Sverdrup (1992b), Sverdrup and Warfvinge (1992) and Alveteg (1998).

The SAFE model has usually been applied with the soil depth limited to the rooting zone. However, there are studies where SAFE has been applied to catchments using estimated average soil depth, and lateral water flow through the soil layers to represent run off chemistry. In Martinson et al. (2003a, b), SAFE was applied to the G1 and the F1 catchment at Lake Gårdsjön, Sweden. The focus there was to add sulphate adsorption/desorption to SAFE. One of the conclusions (2003a) was that prediction of the timing of recovery improved when this process was added. The latter study (2003b) concluded that the long-term influence of adsorption on recovery was limited. In an earlier study, Warfvinge et al. (1995) reported that long-term patterns of lake $\mathrm{pH}$ predicted by SAFE were similar to those reconstructed by paleolimnological investigations.

In this study we use results from a regional application of SAFE to 273 Swedish forest sites, distributed all over Sweden. Input data were parameterised according to $\mathrm{Al}-$ veteg (2004). Soil water chemistry was calculated for each year between 1800 and 2100 . Here we use time series of soil water chemistry at $0.5 \mathrm{~m}$ depth for calculating the F-factor.

\subsubsection{Dividing data according to cumulative acidity}

The cumulative acidity of the precipitation (Eq. 8) reflects the external acid load on the forest sites for a period of time, here 1800-1980:

Cumulative acidity $=\sum_{i=1800}^{1980}$ Acidity $_{i}$

where the cumulative acidity is given in eq $\mathrm{m}^{-2}$.

We have defined the acidity of the precipitation (eq $\mathrm{m}^{-2}$ year $^{-1}$ ) as:

Acidity $=$

Dep $_{\mathrm{SO}_{4}}+$ Dep $_{\mathrm{NO}_{3}}+$ Dep $_{\mathrm{Cl}}+$ Dep $_{\mathrm{NH} 4}-$ Dep $_{\mathrm{Na}}+\mathrm{Ca}+\mathrm{Mg}+\mathrm{K}$

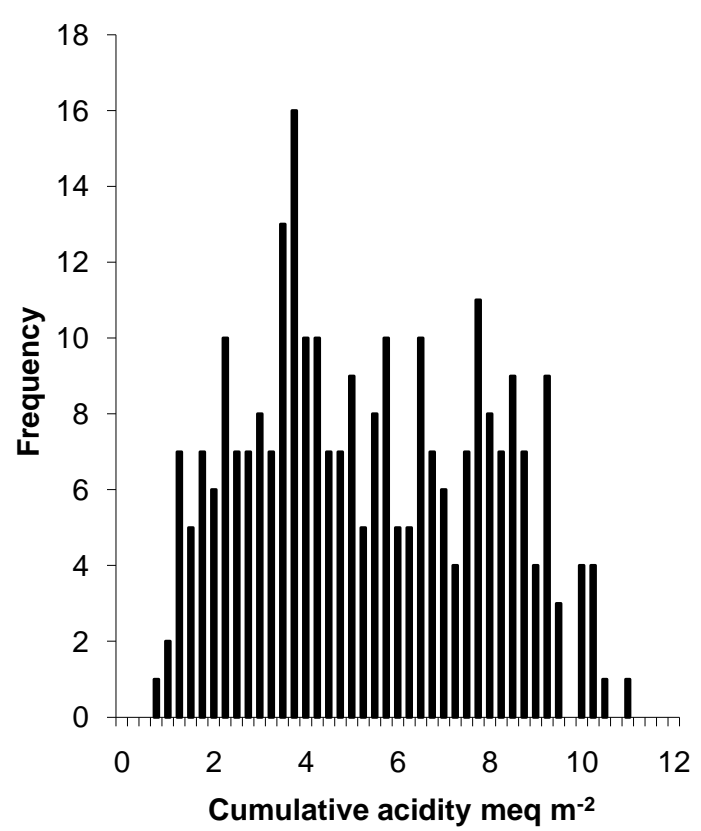

Fig. 1. Frequency plot of cumulative acidity of the precipitation from 1800 to 1980 . Number of forest sites is 273 .

In the SAFE model, all ammonium is assimilated by vegetation or nitrified. That is why $\mathrm{NH}_{4}$ is lumped with the anions of strong acids.

Two subsets of sites were identified by selecting the lowest and uppermost quartile of cumulative acidity corresponding to cumulated deposition acidity below 3.3 and above $7.5 \mathrm{eq} \mathrm{m}^{-2}$ (Fig. 1). The sites from the lowest quartile are located in Northern Sweden, and those from the uppermost quartile are situated near the West Coast of Southern Sweden, (Fig. 2). Hereafter, the subsets will be referred to as "South" and "North".

\subsection{Time series of the F-factor}

\subsubsection{The F-factor from SAFE}

From time series of SAFE soil water chemistry at $0.5 \mathrm{~m}$ depth, we can calculate the F-factor for each year between 1800 and 2100 as defined by Eq. (1). This offers us a way to investigate how $\mathrm{F}$ changes during acidification and recovery. Pre-industrial conditions, $\left[\mathrm{BC}^{*}\right]_{o},\left[\mathrm{SO}_{4}^{*}\right]_{o}$, are given by the situation in 1800 . Thus the F-factor at any year $t$ can be calculated from SAFE as:

$\mathrm{F}_{\mathrm{SAFE}(t)}=\frac{\left[\mathrm{BC}^{*}\right]_{t}-\left[\mathrm{BC}^{*}\right]_{1800}}{\left[\mathrm{SO}_{4}^{*}\right]_{t}-\left[\mathrm{SO}_{4}^{*}\right]_{1800}}$ 


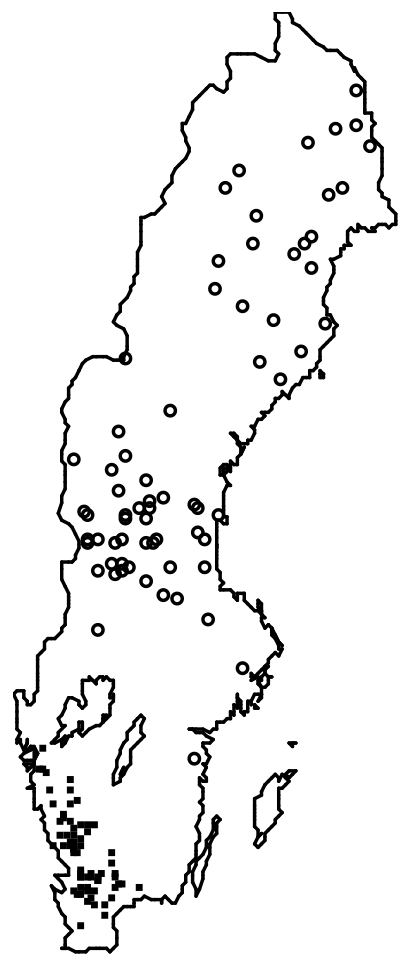

Fig. 2. Location of sites with cumulative acidity higher than $7.5 \mathrm{eq} \mathrm{m}^{-2}(>75 \mathrm{th}$, filled squares in subset South) and lower than $3.3 \mathrm{eq} \mathrm{m}^{-2}(<25$ th, open circles in subset North). Each subset includes 69 forest sites.

\subsubsection{The F-factor from empirical functions}

In practical applications of the SSWC and related models, when no measurements of $\left[\mathrm{BC}^{*}\right]_{o}$ are available, $\mathrm{F}$ has to be estimated. There are three empirical equations in the literature that make use of some aspect of contemporary water chemistry to estimate F:

i) (Brakke et al., 1990):

$$
\begin{aligned}
& \mathrm{F}(t)=\sin \left(\frac{\pi \cdot\left[\mathrm{BC}^{*}\right]_{t}}{2 \cdot 400}\right) \\
& \text { (if }\left[\mathrm{BC}^{*}\right] \mathrm{t}>400 \mu \mathrm{eq} \mathrm{L}^{-1} \text {, then } \mathrm{F}=1 \text { ) }
\end{aligned}
$$

ii) (Bernes, 1991)

$$
\mathrm{F}(t)=0.8 \cdot \arctan \left(0.0043 \cdot\left(\text { alkalinity }_{t}+200\right)\right)
$$

$$
\text { (alkalinity in } \mu \mathrm{eq} \mathrm{L}^{-1} \text { ) }
$$

iii) (Posch et al., 1997):

$$
\begin{aligned}
& \mathrm{F}(t)=1-\exp \left(-\frac{\left[\mathrm{BC}^{*}\right]_{o}}{131}\right) \\
& \left(\left[\mathrm{BC}^{*}\right]_{o} \text { in } \mu \mathrm{eq} \mathrm{L}^{-1}\right)
\end{aligned}
$$

The alkalinity in Eq. (12) in this paper was calculated from ANC (Eq. 14) using the CBalk approach (Bishop et al., 2008) (Eq. 15).

$$
\begin{aligned}
& \mathrm{ANC}_{t}=\left[\mathrm{BC}^{*}\right]_{t}-\left[\mathrm{SO}_{4}^{*}\right]_{t} \\
& \text { alkalinity }_{t}=\mathrm{ANC}_{t}-6.3 \cdot \mathrm{DOC}
\end{aligned}
$$

In the SAFE model, a default value of soil solution DOC equal to $3 \mathrm{mg} \mathrm{L}^{-1}$ is used for the horizon at $0.5 \mathrm{~m}$.

In order to solve Eq. (13), it has to be combined with Eq. (1), so that $\mathrm{F}$ and $\left[\mathrm{BC}^{*}\right]_{o}$ are solved for iteratively. Thus $\mathrm{F}$ is a function of $\left[\mathrm{BC}^{*}\right]_{t}$ as well as $\left[\mathrm{BC}^{*}\right]_{o}$. Note that $\left[\mathrm{BC}^{*}\right]_{1800}$ is not substituted for $\left[\mathrm{BC}^{*}\right]_{o}$, as in Eq. (10). However, we use $\left[\mathrm{SO}_{4}^{*}\right]_{1800}$ as $\left[\mathrm{SO}_{4}^{*}\right]_{o}$ in Eq. (1) because the focus is on investigating the empirical estimates of the F-factor from contemporary water chemistry, and not on different expressions for estimating $\left[\mathrm{SO}_{4}^{*}\right]_{o}$. In practise, $\left[\mathrm{SO}_{4}^{*}\right]_{o}$ is calculated empirically from $\left[\mathrm{BC}^{*}\right]_{t}$, for instance as suggested in Wilander (1994a):

$\left[\mathrm{SO}_{4}^{*}\right]_{o}=5+0.05 \cdot\left[\mathrm{BC}^{*}\right]_{t}$

where the concentrations are given in $\mu \mathrm{eq} \mathrm{L}^{-1}$.

It should be noted that Eqs. (11) and (13) are valid for $\mathrm{F}$ between 0 and 1, while Eq. (12) also is valid for F values outside this interval. In the following, these three expressions for the F-factor, Eqs. (11), (12) and (13), will be referred to as $\mathrm{F}_{\mathrm{BC}^{*}(t)}, \mathrm{F}_{\mathrm{ALK}(t)}$ and $\mathrm{F}_{\mathrm{BC}^{*} o(t)}$. Each of the three empirical F-factors is calculated for every year from 1800 to 2100 and compared to $\mathrm{F}_{\mathrm{SAFE}(t)}$.

\subsection{Time series of the critical load of sulphur}

From time series of runoff chemistry and $\mathrm{F}$ we can calculate the corresponding critical load of sulphur, defined as (UBA, 1996):

$\mathrm{CL}(\mathrm{S})=Q \cdot\left(\left[\mathrm{BC}^{*}\right]_{o}-\mathrm{ANC}_{\text {limit }}\right)-\mathrm{BC}_{u}$

where $\mathrm{CL}(\mathrm{S})$ is the critical load of sulphur (eq ha $\left.{ }^{-1} \mathrm{yr}^{-1}\right), Q$ is the long-term average of runoff and $\mathrm{ANC}_{\text {limit }}$ is the critical chemical value above which no long-term effects occur on aquatic biota.

The non-marine, pre-industrial leaching of base cations, $\mathrm{BC}_{o}^{*}$, is calculated from Eq. (1) using $\mathrm{F}_{\mathrm{SAFE}(t)}, \mathrm{F}_{\mathrm{BC} *(t)}$, $\mathrm{F}_{\mathrm{BC}^{*}(t)}$ and $\mathrm{F}_{\mathrm{ALK}(t)}$. For the sake of simplicity we ignore $\mathrm{BC}_{u}$ in Eq. (17), i.e. we do not take into account that some acidity should be subtracted because of timber harvesting. Therefore, we do not calculate a true CL(S). Nonetheless, for the comparison of different CL(S) due to different F's, this is of no importance as all cases ignore $\mathrm{BC}_{u}$. A default value of $\mathrm{ANC}_{\text {limit }}\left(20 \mu \mathrm{eqL} \mathrm{L}^{-1}\right)$ was selected as it has been used widely for critical load calculations in Sweden (Henriksen et al., 1992; Posch et al., 1997; Rapp et al., 2001a). 


\section{Results}

\subsection{The dynamics of the F-factor}

The F-factor indicated by the SAFE model changes dramatically over the years (Fig. 3). In the South, the F-factor varies between 0.9 and 1.4 for the first hundred years, taking into account $50 \%$ of all data sites. After 1900, F decreases and turns negative at about 1980. Between 2010 and $2030 \mathrm{~F}$ varies between -0.8 and -1.4 , whereupon it starts increasing gradually until it turns positive in 2100 . The F-factor in the North follows the same pattern but the changes are not as large as in the South.

The F-factors estimated from empirical relationships, $\mathrm{F}_{\mathrm{BC}^{*}(t)}, \mathrm{F}_{\mathrm{BC}^{*} o(t)}$ and $\mathrm{F}_{\mathrm{ALK}(t)}$ do not change as dramatically as $\mathrm{F}_{\mathrm{SAFE}(t)}$, (Fig. 3). $\mathrm{F}_{\mathrm{BC}^{*}(t)}$, and $\mathrm{F}_{\mathrm{BC}^{*} o(t)}$ in the South vary between 0 and 1 , starting from $0.2-0.5$ in 1800 and then gradually increasing to $0.2-1.0$ in 1970 , whereupon they decrease and level out at zero between 2000 and 2030. Eventually, $\mathrm{F}_{\mathrm{BC}^{*}(t)}$ and $\mathrm{F}_{\mathrm{BC}^{*} o(t)}$ increase slightly to $0-0.4$ in 2100 . $\mathrm{F}_{\mathrm{ALK}(t)}$ in the South starts with an F of 0.6 and is stable until 1950, when it starts decreasing and turns negative at 1970. Between 1950 and $2000 \mathrm{~F}_{\mathrm{ALK}(t)}$ varies between -0.4 and 0.6. Around 1990, $\mathrm{F}_{\mathrm{ALK}(t)}$ turns positive again whereupon it increases gradually to $0.4-0.6$ in 2100 . Similar to $F_{\text {SAFE }}$, the changes in the North for $\mathrm{F}_{\mathrm{BC}^{*}(t)}, \mathrm{F}_{\mathrm{BC}^{*} o(t)}$ and $\mathrm{F}_{\mathrm{ALK}(t)}$ show the same pattern but the variations are smaller.

The discrepancies between the empirical F's and FSAFE become more evident if the difference between each $\mathrm{F}$ and $\mathrm{F}_{\mathrm{SAFE}(t)}$ is plotted versus time, (Fig. 4). In the South, Ffactors from empirical relationships tend to underestimate $\mathrm{F}$ during the first 130 years after 1800 . Then, between 1930 and 1990 the discrepancies become smaller, whereupon the discrepancies start increasing again. In the North, for the first 180 years, the F-factors are in reasonable agreement with $\mathrm{F}_{\mathrm{SAFE}(t)}$ but then after 1980 the discrepancies become as large as for the south.

The large difference between $\mathrm{F}_{\mathrm{SAFE}(t)}$ and empirical F's after 1990 have to do with the negative F's predicted by the SAFE model. The F-factor turns negative because $\left[\mathrm{BC}^{*}\right]_{t}$ decreases below $\left[\mathrm{BC}^{*}\right]_{o}$ in Eq. (1), provided that $\left[\mathrm{SO}^{*}\right]_{t}$ does not decrease below $\left[\mathrm{SO}_{4}^{*}\right]_{o}$. This lower $\left[\mathrm{BC}^{*}\right]_{t}$ occurs after a period when acid deposition has depleted the soil store of $\mathrm{BC}$, and then $\mathrm{S}$ deposition declines, reducing the leaching of $\mathrm{BC}$ to levels below those in the pre-industrial era.

A general overview of all $\mathrm{F}$ values, for year and site is given in Table 1. The variation in $\mathrm{F}$ for the study sites, expressed as differences between the 95 th and 5 th percentile, is largest for $\mathrm{F}_{\mathrm{SAFE}(t)}$. The variation of $\mathrm{F}_{\mathrm{BC}^{*}(t)}$ and $\mathrm{F}_{\mathrm{BC}^{*} o(t)}$ is much smaller. This has to do with Eqs. (9) and (11) being defined for $\mathrm{F}$ values between 0 and $1 . \mathrm{F}_{\mathrm{BC}^{*}(t)}$ and $\mathrm{F}_{\mathrm{BC}^{*} o(t)}$ show about the same dynamics, (Fig. 3), which is expected as both are functions of $\left[\mathrm{BC}^{*}\right]_{t}$. Note that even though Eq. (11) is a function of only $\left[\mathrm{BC}^{*}\right]_{o}$, it has to be solved together with Eq. (1), and thus $\mathrm{F}_{\mathrm{BC}^{*} o(t)}$ is indeed de-
Table 1. F-factors of all years $(n=301)$ and sites $(n=138)$.

\begin{tabular}{lrrrrr}
\hline & \multicolumn{5}{c}{ Percentiles } \\
& 5th & 25th & 50th & 75th & 95th \\
\hline $\mathrm{F}_{\mathrm{SAFE}(t)}-1.3$ & -0.4 & 0.4 & 0.7 & 1.3 \\
$\mathrm{~F}_{\mathrm{BC}}{ }^{*}(t)$ & 0.0 & 0.1 & 0.2 & 0.4 & 1.0 \\
$\mathrm{~F}_{\mathrm{BC}}^{*} o(t)$ & 0.0 & 0.1 & 0.3 & 0.5 & 0.8 \\
$\mathrm{~F}_{\mathrm{ALK}(t)}(t)$ & 0.2 & 0.5 & 0.6 & 0.6 & 0.8 \\
\hline
\end{tabular}
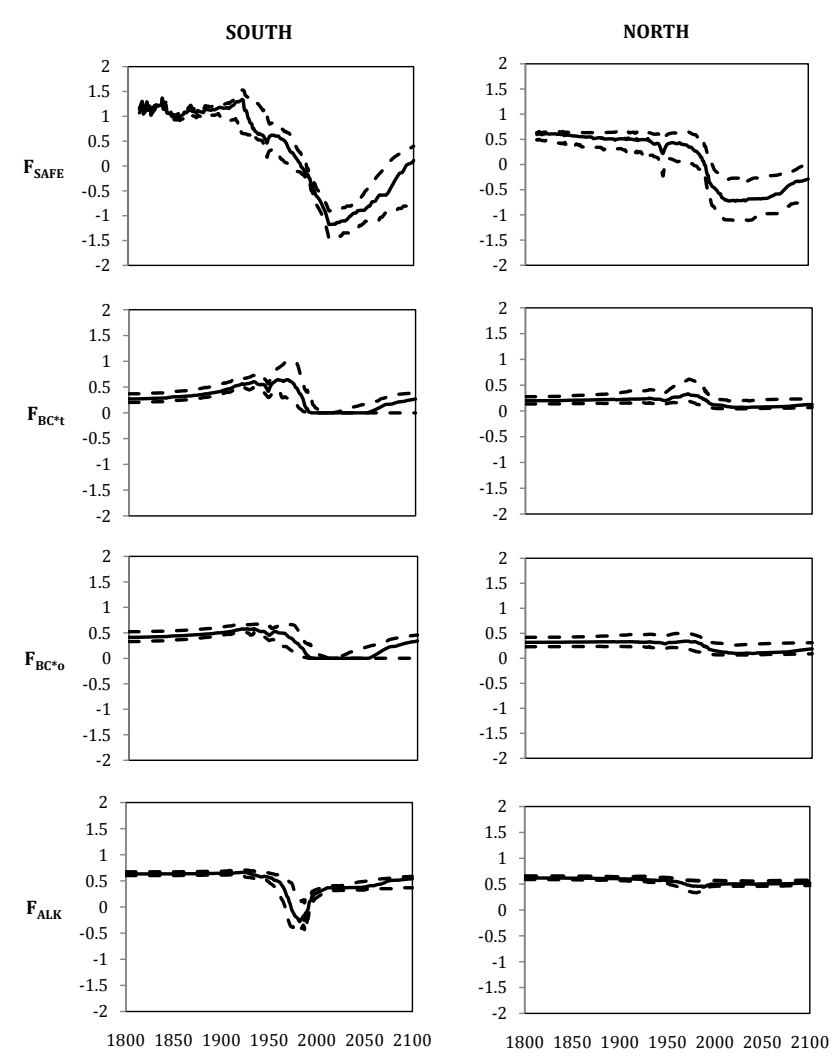

Fig. 3. F-factors calculated by the SAFE model, $\mathrm{F}_{\mathrm{SAFE}}$, and estimated by empirical relationships, $\mathrm{F}_{\mathrm{BC}^{*}(t)}, \mathrm{F}_{\mathrm{BC}^{*} o(t)}$ and $\mathrm{F}_{\mathrm{ALK}(t)}$, for South and North using $\left[\mathrm{BC}^{*}\right]_{t}$ and $\left[\mathrm{SO}_{4}^{*}\right]_{t}$ generated by SAFE for each year in the time series. The 25 th, 50 th and 75 th percentiles are shown, thus $50 \%$ of the North and South sites have values between the upper and lower lines. "North" and "South" represent sites with low and high cumulative acid deposition, respectively.

pendent on $\left[\mathrm{BC}^{*}\right]_{t}$. The variation of $\mathrm{F}_{\mathrm{ALK}(t)}$ is the smallest of all F's. $\mathrm{F}_{\mathrm{ALK}(t)}$ is a continuous function of present alkalinity, which is clearly demonstrated. Alkalinity in the North has changed moderately compared to the South (Fig. 3). As a consequence, $\mathrm{F}_{\mathrm{ALK}(t)}$ for the South decreases dramatically, in contrast to the North. An interesting feature of $\mathrm{F}_{\mathrm{ALK}(t)}$ is that it produces F-factors less than zero (Fig. 3), as also found in $\mathrm{F}_{\mathrm{SAFE}(t)}$. The discrepancies between $\mathrm{F}_{\mathrm{SAFE}(t)}$ and $\mathrm{F}_{\mathrm{ALK}(t)}$ are larger than between $\mathrm{F}_{\mathrm{SAFE}(t)}$ and either $\mathrm{F}_{\mathrm{BC}(t)}$ or $\mathrm{F}_{\mathrm{BC}^{*} o(t)}$. 

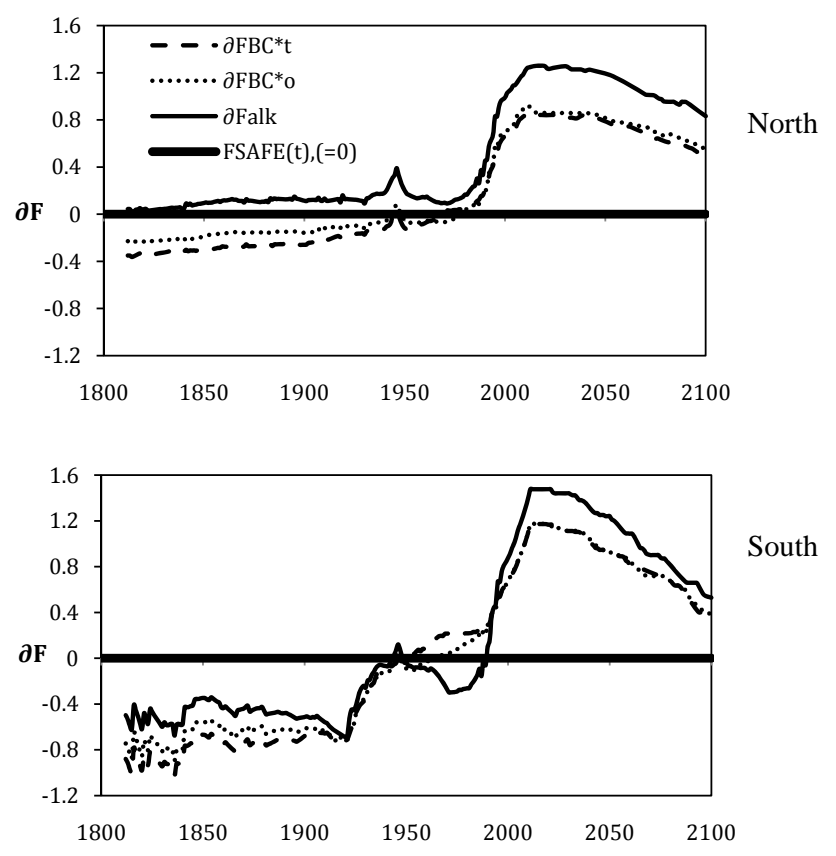

Fig. 4. Deviation (the 50th percentile) from $\mathrm{F}_{\mathrm{SAFE}(t)}$ expressed as $\partial \mathrm{F}_{i}=\mathrm{F}_{i}-\mathrm{F}_{\mathrm{SAFE}}(t)$ where $i=\mathrm{BC}^{*}(t), \mathrm{BC}_{o}^{*}(t)$ and $\operatorname{ALK}(t)$ for North (top) and South. "North" and "South" represent sites with low and high cumulative acid deposition, respectively.

\subsection{The F-factor and $\mathrm{CL}(\mathrm{S})$}

There are considerable discrepancies between $F_{\text {SAFE }}$ and $\mathrm{F}$ calculated from empirical relationships. Therefore, the critical load of sulphur will differ as well, (Fig. 5). As $\mathrm{F}_{\mathrm{SAFE}}$ is calculated from Eq. (1), $\mathrm{CL}(\mathrm{S})_{\mathrm{FSAFE}(t)}$ will be constant and the variation of $\mathrm{CL}(\mathrm{S})_{\mathrm{FBC}^{*}(t)}, \mathrm{CL}(\mathrm{S})_{\mathrm{FBC}^{*} o(t)}$ and $\mathrm{CL}(\mathrm{S})_{\mathrm{FALK}(t)}$ is caused by how these empirical F-factors respond to the variation in water chemistry predicted by SAFE over time as acid deposition changes.

In the North, $\mathrm{CL}(\mathrm{S})$ calculated by $\mathrm{F}_{\mathrm{BC}^{*} o(t)}$ and $\mathrm{F}_{\mathrm{BC} *(t)}$ are fairly constant until 1980. Then $\mathrm{CL}(\mathrm{S})$ decreases as $\mathrm{F}_{\mathrm{BC}^{*}(t)}$ and $\mathrm{F}_{\mathrm{BC}} *(t)$ overestimate $\mathrm{F}$ in comparison with $\mathrm{F}_{\mathrm{SAFE}(t)}$. $\mathrm{CL}(\mathrm{S})_{\mathrm{FALK}(t)}$ starts decreasing about 1900.

In the South, the variation in CL(S) predicted by the empirical F's is greater, which is expected since the deposition has changed more compared to the North. In addition, variations in soil characteristics are larger in the South. For the first 150 years $\mathrm{CL}(\mathrm{S})_{\mathrm{FBC}^{*}(t)}, \mathrm{CL}(\mathrm{S})_{\mathrm{FBC}^{*} o(t)}$ and $\mathrm{CL}(\mathrm{S})_{\mathrm{FALK}(t)}$ are about the same. After $1950 \mathrm{CL}(\mathrm{S})_{\mathrm{FBC}^{*}(t)}$ and $\mathrm{CL}(\mathrm{S})_{\mathrm{FBC}^{*} o(t)}$ decrease as in the North. The rapid increase in CL(S) FALK $(t)$ is caused by a decrease in alkalinity so that $\mathrm{F}_{\mathrm{ALK}(t)}$ turns negative (Fig. 3 and Eq. 10). After $1980 \mathrm{CL}(\mathrm{S})_{\mathrm{FALK}(t)}$ decreases as in the North.
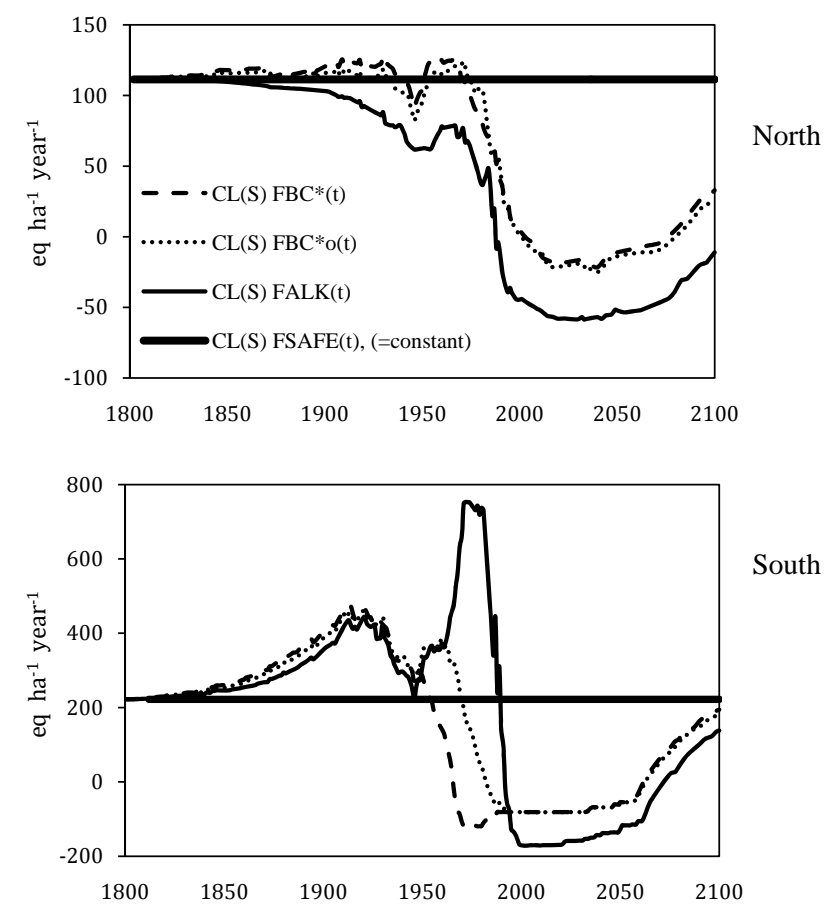

Fig. 5. Time series of the critical load of sulphur (the 50th percentile), eq ha ${ }^{-1}$ year $^{-1}$, for the North (top) and the South of Sweden as estimated from the empirical F-factors. Note that according to the theory behind the SSWC model and critical load estimates, these CL (and pre-industrial chemistry) should have been a stable feature of each site that does not change with the year " $t$ " in which an estimate of $\mathrm{CL}(\mathrm{S})$ and $\left[\mathrm{BC}^{*}\right]_{o}$ is made from contemporary water chemistry. "North" and "South" represent sites with low and high cumulative acid deposition, respectively.

\section{Discussion}

\subsection{The dynamics of $F$}

In this paper we have explored the F-factor with an emphasis on its dynamic nature during acidification and recovery. Particular regard has been paid to how well the SSWC model can predict a stable, steady-state, pre-industrial water chemistry, (and the associated CL) from contemporary water chemistry that changes as acidification and any subsequent recovery progress. The use of a dynamic biogeochemical model, in this case SAFE, is essential as it takes into account the interaction between the solid and the liquid phase in the catchment, which is exactly the function to be simulated by the F-factor.

The results suggest that the real $\mathrm{F}$, here represented by $\mathrm{F}_{\mathrm{SAFE}(t)}$, declines from a positive value during the acidification phase and then turns negative during the recovery phase. A positive $F$ means that soils neutralise inputs of acidity. Theoretically, the F-factor turns negative during recovery when the depleted base cation storage slowly is replenished by means of weathering and $\mathrm{BC}$ deposition. During 
the replenishment phase, the concentration of base cations in runoff can fall below the pre-industrial level. Naturally, weathering, $\mathrm{BC}$ deposition and forest harvesting are not constant in time, nor in the SAFE model, so there are several combinations of factors contributing to negative F-values. A negative $\mathrm{F}$ value is also discussed in Brakke et al. (1990) where the authors claim that negative F-factors are possible after a large reduction in sulphur deposition. Even F-values higher than 1 were predicted by SAFE during the first 150 years for the South. This happens when $\left[\mathrm{BC}^{*}\right]_{t}$ increases more than $\left[\mathrm{SO}_{4}^{*}\right]_{t}$ in Eq. (1). This in turn suggests that the acidity of the precipitation decreased for a time period due to increasing deposition of anthropogenic base cations. Sullivan et al. (1990) used diatom data from Adirondack lakes for estimating F-factors, and they found values ranging from 0.5 to 1.5. Thus it seems that F-values less than 0 and larger than 1 , as calculated by the SAFE model, are indeed reasonable and have been reported by other studies (Brakke et al., 1990; Sullivan et al., 1990).

Even though the North, with a small cumulative acidity, is much less acidified than the South, the F-factor indeed turns negative during the recovery period there as well. It seems likely that the F-factor is very sensitive to small changes in soil- or runoff chemistry. Therefore, even a moderate recovery phase has a significant impact on the $\mathrm{F}$ values.

This study suggests that although the empirical $F$ values were not so far off from $\mathrm{F}_{\mathrm{SAFE}(t)}$ during the time when the Ffactor was introduced, around 1980, they all deviate substantially from $\mathrm{F}_{\mathrm{SAFE}(t)}$ during the recovery phase. This implies a variation in the pre-industrial surface water chemistry, and $\mathrm{CL}$, estimated from the empirical F-factors. Changing estimates of the steady-state pre-industrial water chemistry at a site is manifestly incorrect, and indicates that the empirical F-factors are not well suited to the situation when soils starts recovering after a decline in acid deposition. $\mathrm{F}_{\mathrm{ALK}(t)}$ is a special case as it turns negative for the sites exposed to high acid loads, though at a different time than $\mathrm{F}_{\mathrm{SAFE}(t)}$. Thus the estimated critical loads from empirical $\mathrm{F}$ functions and water chemistry during recovery would be too low.The negative Ffactors for $\mathrm{F}_{\mathrm{ALK}(t)}$ correspond to a low alkalinity in runoff, not a decline in acid deposition as for $\mathrm{F}_{\mathrm{SAFE}(t)}$. The implications of these discrepancies on critical loads as calculated from the SSWC for official Swedish national data from 1995 (Rapp et al., 2002) are discussed in a later section.

\subsection{Short- and long-term variation of $C L(S)$}

An important feature of the critical load concept is the longterm perspective. Input data should as far as possible represent long-term averages. Moreover, input data, criteria and processes should be formulated so as to attain a longterm sustainability. Effects of short-term variation in climate, and thus water chemistry, on critical load estimates can be minimised by averaging over a series of measurements. Temporal averaging, however, can be problematic since a large amount of data is needed to attain spatial representativity. Swedish CL calculations have, therefore, been based on a few lake surveys with the possibility that the results are affected by the lack of a reliable average for the water chemistry in the lakes sampled. Even with use of more dynamic models, this balance between spatial representativity and temporal stability must be considered.

A more serious and fundamental drawback of SSWC was demonstrated by this study which showed that the surface water critical load estimated for a site changes with the phase of acidification/recovery when a lake is sampled. We refer to this as the long-term variation. This feature of SSWC is fundamentally contrary to the critical load concept, which treats the $\mathrm{CL}$ as an inherent property of an ecosystem. In theory, even if lake surveys in 1900 and 1980 overcame the problem of short-term variations in surface water chemistry, they would give very different estimates of the critical load (and pre-industrial chemistry). The latter survey, in the acidification phase, would generally give significantly lower critical loads. A subsequent lake survey, during the recovery period, would give yet another CL and pre-industrial chemistry. The critical load would be too low as the F-factor is too high in comparison with the "true" F-factor. The only way to resolve this problem would be to find an empirical formulation that gave the true F-factors based on a sample of surface water chemistry at any point in time. That, however, is a challenge that remains to be addressed.

An alternative approach to calculate CL, that would circumvent the problem with changing lake chemistry, is to use soil properties (Rapp and Bishop, 2003). There are, however, challenges with that approach as well, especially in terms of data acquisition and how to define the catchment hydrology. Nevertheless, the promise of a surface water CL based on soil properties is that it would be more stable than lake chemistry.

It should be noted that critical load mapping has moved towards dynamic modelling that includes the variation of soiland lake chemistry over time (Warfvinge et al., 1992). Steady state models that worked reasonably well when acid deposition was large, are being replaced by more realistic acidification models but also much more data intensive models. Dynamic models offer more possibilities to relate model results to observed data in contrast to steady state models where exceedances does not necessarily indicate current damage. In Curtis et al. (2001) the relationship between exceedance of the critical load and current chemistry is explored in a way which also involves the dynamic aspect of the F-factor.

Another feature of the long-term variation is increasing trends in DOC observed across much of the $\mathrm{N}$ Hemisphere here (Monteith et al., 2007). This DOC increase has implications for the calculations of pre-industrial chemistry because the acid/base status of the water will increase (Erlandsson et al., 2008). 
Table 2. Results of F-factor scenarios expressed as the proportion of exceeded lakes and the total amount of exceedances. Note that a negative exceedance (critical load is not exceeded) is set to zero.

\begin{tabular}{lcc}
\hline Scenarios & $\begin{array}{c}\text { Proportion of } \\
\text { exceeded lakes } \%\end{array}$ & $\begin{array}{c}\text { Exceedance } \\
\text { eq ha }\end{array}$ \\
\hline 1. Standard case & 22 & 1530 \\
2. F standard $-50 \%$ & 14 & 1380 \\
3. F standard -0.3 & 15 & 1330 \\
4. F standard -0.6 & 9 & 950 \\
\hline
\end{tabular}

\subsection{How important is the F-factor, really?}

The comparison between $\mathrm{F}_{\mathrm{SAFE}(t)}$ calculated directly from the SAFE water chemistry time series, and F's calculated from the same time series using the empirical relationships employed in critical load calculations revealed that $\mathrm{F}_{\mathrm{SAFE}}$, in general, is lower than $\mathrm{F}_{\mathrm{BC}^{*}(t)}, \mathrm{F}_{\mathrm{BC}^{*} o(t)}$ and $\mathrm{F}_{\mathrm{ALK}(t)}$ after about 1990. Even if we do not claim that SAFE provides us with the "truth", the result suggests that the expressions of F, widely used in calculations of critical load of acidity, misses an important link to soil chemistry during the recovery phase and will thus give estimates of both critical load and preindustrial chemistry that depend on the phase of catchment acidification/recovery.

In 2003 the official critical loads for Sweden were based on a lake survey carried out in 1995 (Rapp et al., 2002). From the developments in this paper, there is reason to believe that the F-factors used in these calculations are overestimated. In order to evaluate the importance of $F$ for the CL calculations, four different exceedance scenarios were carried out using $\mathrm{F}_{\mathrm{BC}}{ }_{(t)}$, which was the method employed in calculation of Sweden's surface water critical loads from 1990 to 2003. The first-order acidity balance (FAB) model (Posch et al., 1997) was used for this instead of SSWC, but the role of the Ffactor is exactly the same when SSWC is embedded in FAB as when SSWC is used on its own.

1. Standard case, $F$ is calculated from Eq. (11)

2. Decrease all F's by $50 \%$

3. Decrease all F's by 0.3

4. Decrease all F's by 0.6

The results are presented as the 95 th percentile of exceedance on the sub-EMEP grid $\left(50 \times 50 \mathrm{~km}^{2}\right)$, across Sweden using deposition data from 1997 (Kindbom et al., 2001), (Fig. 6). The sum of all exceedances and the proportion of exceeded lakes are also presented (Table 2).

The standard scenario results in $22 \%$ exceedance of the lakes included in the calculations and the total exceedance is $1530 \mathrm{eq} \mathrm{ha}^{-1}$ year $^{-1}$. Lakes with large exceedance are situated in Southern Sweden, and the West Coast in particular,
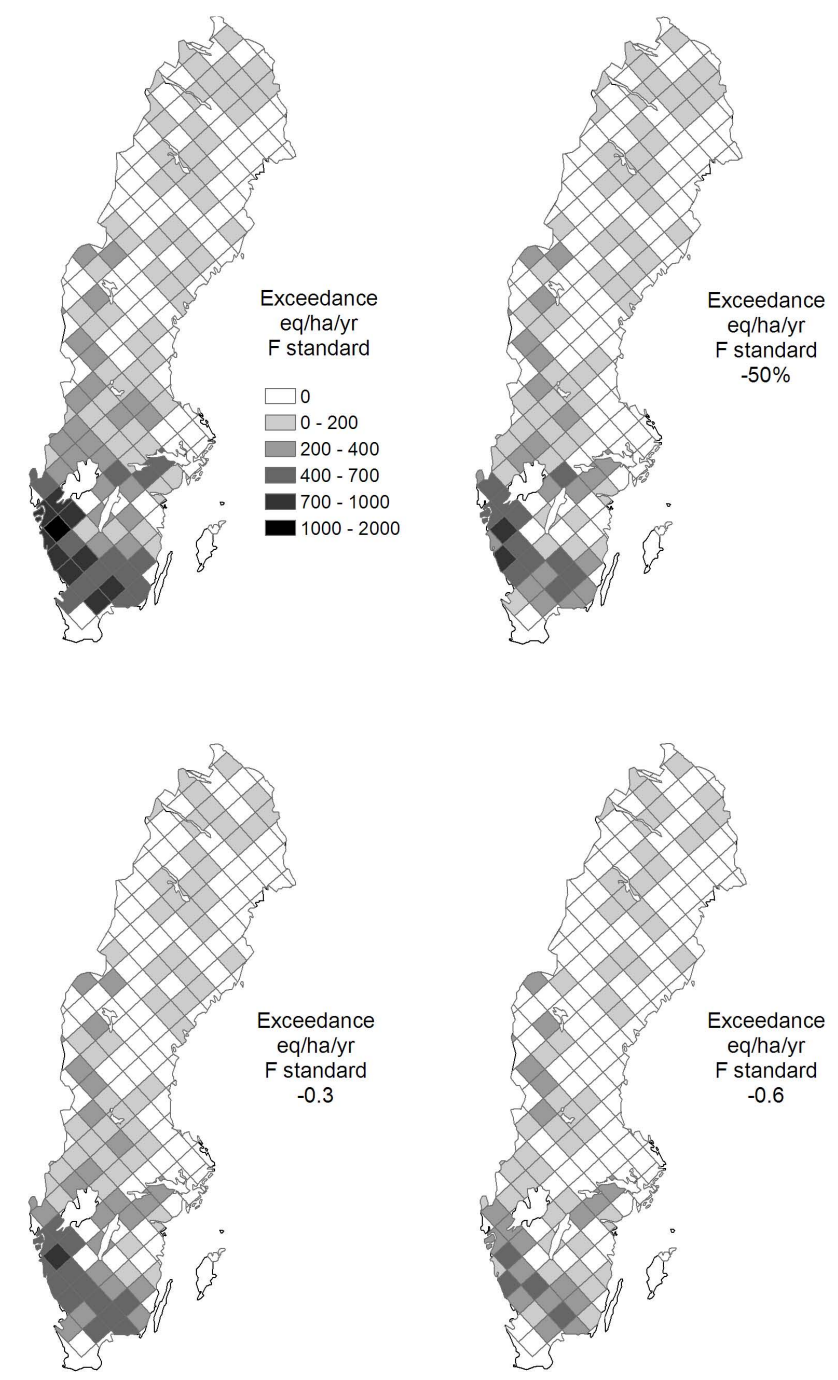

Fig. 6. Exceedance $(\mathrm{S}+\mathrm{N})$ of critical load for Swedish lakes using different "F-factor scenarios", expressed as 95th percentile in each $2500 \mathrm{~km}^{2}$ square. The first-order acidity balance (FAB) model, considering sulphur and nitrogen simultaneously, has been used. The calculations are based on 2377 lakes. Deposition data are from 1997, eq $\mathrm{ha}^{-1} \mathrm{yr}^{-1}$.

where acid deposition is greatest. If the F-factor is decreased by $50 \%$, the proportion of exceeded lakes falls to $14 \%$ and the exceedance falls to $1380 \mathrm{eq} \mathrm{ha}^{-1}$ year $^{-1}$. The result of scenario 3 when the F-factor is decreased by an absolute amount of 0.3 , thus including $6 \%$ negative $F$ values, is about the same as in scenario 2. It appears that there are a great number of lakes with small exceedances as the exceedances do not decrease as much as the proportion of exceeded lakes. Scenario 4, including about $20 \%$ negative $\mathrm{F}$ values should be interpreted as an extreme scenario but in accordance with $\mathrm{F}_{\mathrm{SAFE}}(t)$. In this case, the proportion of exceeded lakes becomes $9 \%$ and the exceedance falls to $950 \mathrm{eq} \mathrm{ha}^{-1}$ year $^{-1}$. 
In Henriksen (1995) the importance of uncertainties in $\mathrm{F}$ was evaluated. The author concluded that $\mathrm{F}$ was not a large source of uncertainty in comparison with the critical chemical value, $\mathrm{ANC}_{\text {limit }}$. In that study, however, only $\mathrm{F}$ values between 0 and 1 were considered and thus the uncertainties associated with $\mathrm{F}$ were smaller.

\section{Conclusions}

Our results suggest that while the F-factor worked best within the acidification phase when it was introduced, the empirical $\mathrm{F}$ functions used for estimating $\mathrm{F}$ will be significantly in error during the recovery phase, when acid deposition has gone down considerably. The reason is that the F-factor should turn negative when the concentrations of base cations decrease below the pre-industrial level during the recovery phase, provided that the predictions of the SAFE model are reasonable. As a consequence, critical loads would be too low during the recovery phase if the empirical $\mathrm{F}$ functions were used to estimate the F-factor. Another important issue we want to emphasise is the way in which models such as SSWC will give different estimates of pre-industrial conditions (and therefore critical loads) depending on when a lake is sampled in the course of its acidification/recovery. This is a fundamental drawback that is not consistent with the concept of critical loads where the aim is to capture the longterm steady-state chemistry in the pre-industrial period, as a basis for calculating the ability of a site to tolerate a specific level of sustained acid deposition.

Acknowledgements. The authors would like to thank Mattias Alveteg, Lund University, for providing results from the SAFE model. Funding has been provided by the Swedish EPA and the SLU Environmental Data Centre.

Edited by: J. Pomeroy

\section{References}

Alveteg, M.: Dynamics of forest soil chemistry. Doctoral thesis, Department of Chemical Engineering II, Lund University, Lund, Sweden, 198 pp., 1998.

Alveteg, M.: Projecting regional patterns of future soil chemistry status in Swedish forests using SAFE, Water Air Soil Pollut., Focus, 49-59, 2004.

Bernes, C.: Acidification and liming of Swedish Freshwaters, Monitor 12, Swedish Environmental Protection Agency, Sweden, 1991.

Binkley, D. and Högberg, P.: Does atmospheric deposition of nitrogen threaten Swedish forests, Forest Ecol. Manag., 92, 119-152, 1997.

Bishop, K., Rapp, L., Köhler, S., and Korsman, T.: Testing the steady-state water chemistry model predictions of pre-industrial lake $\mathrm{pH}$ with paleolimnological data from northern Sweden, Sci. Total Environ., 407, 723-729, 2008.
Brakke, D. F., Henriksen, A., and Norton, S. A.: A variable F-factor to explain changes in base cation concentrations as a function of strong acid deposition, Verh. Verein. Int. Limnol., 24, 146-149, 1990.

Curtis, C. J., Reynolds, B., Allott, T. E. H., and Harriman, R.: The Link Between the Exceedance of Acidity Critical Loads for Freshwaters, Current Chemical Status and Biological Damage: A Re-Interpretation, Water Air Soil Pollut. Focus, 1(1-2), 399413, 2001.

Curtis, C. J., Botev, I., Camarero, L., Catalan, J., Cogalniceanu, D., Hughes, M., Kernan, M., Kopáek, J., Korhola, A., Psenner, R., Rogora, M., Stuchlík, E., Veronesi, M., and Wright R. F.: Acidification in European mountain lake districts: a regional assessment of critical load exceedance, Aquat. Sci., 67(3) 237-251, 2005.

De Vries, W.: Methodologies for the assessment and mapping of critical loads and of the impact of abatement strategies on forest soils, The Winand Staring Centre for Integrated Land, Soil and Water Research, 109, Wageningen, The Netherlands, 1991.

Dickson, W.: Properties of acidified waters. Ecological impact of acid precipitation, in: Sandefjord, Drablös, D., and Tollan, A. (Eds.): SNSF project, Oslo, Norway, 75-83, 1980.

Dupont, J. J., Clair, T. A., Gagnon, C., Jeffries, D. S., Kahl, J. S., Nelson, S. J., and Peckenham, J. M.: Estimation of Critical Loads of Acidity for Lakes in Northeastern United States and Eastern Canada, Environ. Monit. Assess., 109, 275-291, 2005.

Erlandsson, M., Folster, J., Laudon, H., Weyhenmeyer, G. A., and Bishop, K.: Natural variability in lake $\mathrm{pH}$ on seasonal, interannual and decadal time scales: Implications for assessment of human impact, Environ. Sci. Technol., 42(15), 5594-5599, doi:10.1021/es8005157, 2008.

Fölster, J.: Catchment Hydrochemical Processes Controlling Acidity and Nitrogen in Forest Stream Water, Ph.D. thesis, Department of Environmental Assessment, Swedish University of Agricultural Sciences, 124, Uppsala, Sweden, 2001.

Henriksen, A., Forsius, M., Kämäri, J., Posch, M., and Wilander, A.: Exceedance of critical loads in Finland, Norway and Sweden: Reduction requirements for nitrogen and sulphur deposition, Norwegian Institute for Water Research (NIVA), 46, Oslo, Norway, 1993.

Henriksen, A., Kämäri, J., Posch, M., and Wilander, A.: Critical Loads of Acidity, Nordic Surface Waters, Ambio, 21(5), 356363, 1992.

Henriksen, A., Kämäri, J., Posch, M., Lövblad, G., Forsius, M., and Wilander, A.: Critical Loads to Surface Waters in Fennoscandia, Nordic Council of Ministers, 34, Copenhagen, Denmark, 1990.

Henriksen, A.: A simple approach for identifying and measuring acidification of freshwaters, Nature, 278, 542-544, 1979.

Henriksen, A.: Changes in base cation concentrations due to freshwater acidification, Verh. Internat. Verein. Limnol., 22, 692-698, 1984.

Henriksen, A.: Changes in base cations concentrations due to freshwater acidification, Norwegian Institute for Water Research, 50, Oslo, Norway, 1982.

Henriksen, A.: Critical loads of acidity to surface waters - How important is the F-factor in the SSWC method? Water, Air Soil Pollut., 85, 2437-2441, 1995.

Hettelingh, J. P., Posch, P., and Slootweg, J.: Critical Load, Dynamic Modelling and Impact Assessment in Europe, CCE Sta- 
tus Report 2008, Report 500090003. Coordination Center for Effects, Netherlands Environmental Assessment Agency, The Netherlands, 2008.

Kindbom, K., Svensson, A., Sjöberg, K., and Persson, C.: Nationell miljöövervakning av luft- och nederbördskemi 1997, 1998 och 1999. Nr 96 /IVL, Rapport B 1420. Swedish Environmental Research Institute, Swedish Meteorological and Hydrologocal Institute, Göteborg och Norrköping, Sweden, 2002 (in Swedish with English abstract).

Martinson, L., Alveteg, M., and Warfvinge, P.: Parameterization and evaluation of sulfate adsorption in a dynamic soil chemistry model, Environ Pollut., 124, 119-125, 2003a.

Martinson, L., Alveteg, M., Mörth, C.-M., and Warfvinge, P.: The effect of changes in natural and anthropogenic deposition on modelling recovery from acidification, Hydrol. Earth Syst. Sci., 7, 766-776, 2003b, http://www.hydrol-earth-syst-sci.net/7/766/2003/.

Monteith, D. T., Stoddard, J. L., Evans, C., de Wit, H., Forsius, M., Hogasen, T., Wilander, A., Skelkvale, B. L., Jeffries, D. S., Vuorenmaa, J., Keller, B., Kopacek, J., and Vesely, J.: Dissolved organic carbon trends resulting from changes in atmospheric deposition chemistry, Nature, 450, 537-541, 2007.

Nilsson, J. and Grennfelt, P. (Eds.): Critical loads for sulphur and nitrogen. UNECE/Nordic Council workshop report, Skokloster, Sweden, March 1988, Nordic Council of Ministers, Copenhagen, 1988.

Posch, M., de Smet, P. A. M., Hettelingh, J. P., and Downing, R. J.: Calculation and Mapping of Critical Thresholds in Europe, Status Report 1999, Coordination Center for Effects, National Institute of Public Health and the Environment (RIVM), 165, Bilthoven, The Netherlands, 1999.

Posch, M., Kämäri, J., Forsius, M., Henriksen, A., and Wilander, A.: Exceedance for Lakes in Finland, Norway and Sweden: Reduction requirements for acidifying nitrogen and sulfur deposition, Environ. Manage., 21(5), 291-304, 1997.

Rapp, L. and Bishop, K.: Modeling Surface Water Critical Loads with PROFILE: Possibilities and Challenges, J. Environ Qual., 32, 2290-2300, 2003.

Rapp, L., Wilander, A., and Bertills, U.: Kritisk belastning för försurning av sjöar, in: Kritisk belastning för svavel och kväve, edited by: Bertills, U. and Lövblad, G., Rapport 5174, Swedish Environmental Protection Agency, Stockholm, Sweden, 2002 (in Swedish with English abstract).
SEPA: Bara naturlig försurning, Underlagsrapport till fördjupad utvärdering av miljömålsarbetet, Rapport 5766, Swedish Environmental Protection Agency, Sweden, 2007 (in Swedish with English abstract).

Sullivan, T. J., Charles, D. F., Smol, J. P., Cummings, B. F., Selle, A. R., Thomas, D. R., Bernert, J. A., and Dixit, S. S.: Quantification of changes in lakewater chemistry in response to acidic deposition, Nature, 345, 54-58, 1990.

Sverdrup, H. and Warfvinge, P.: Calculating field weathering rates using a mechanistic geochemical model PROFILE, Appl. Geochem., 8, 273-283, 1992.

UBA.: Manual on methodologies and criteria for mapping critical levels/loads and geographical areas where they are exceeded, UN/ECE Conventionon Long-range Transboundary Air Pollution, Federal Environmental Agency (Umweltbundesamt), Texte 71/96, Berlin, Germany, 1996.

UNECE.: The 1999 Gothenburg Protocol to Abate Acidification, Eutrophication and Ground-level Ozone, online available at: www.unece.org, 1999.

Warfvinge, P., Holmberg, M., Posch, M., and Wright, R. F.: The Use of Dynamic Models to Se Target Loads, Critical Loads in Nordic Countries, Ambio, 21(5), 369-376, 1992.

Warfvinge, P., Sverdrup, H., Alveteg, M., and Rietz, F.: Modelling Geochemistry and Lake pH Since Glaciation at Lake Gårdsjön, Water, Air Soil Pollut., 85, 713-718, 1995.

Warfvinge, P. and Sverdrup, H.: Hydrochemical modeling, in: Sandén, P, and Warfvinge, P., (Eds.), Modelling Groundwater Response to Acidification, Swedish Meteorological and Hydrological Institute (SMHI), Norrköping, Sweden, 79-114, 1992a.

Warfvinge, P. and Sverdrup, H.: Calculating Critical Loads of Acid Deposition with Profile-A Steady State Soil Chemistry Model, Water Air Soil Pollut., 63, 119-143, 1992b.

Watmough, S. A., Aherne, J., and Dillon, P. J.: Effect of Declining Lake Base Cation Concentration on Freshwater Critical Load Calculations, Environ. Sci. Technol., 39(9), 3255-3260, 2005.

Wilander, A.: Calculations of acidification in Norrbotten county, in: Critical loads for acidification of surface waters in Northern Fennoscandia, Nordkalottkommiteens publikasjonsserie Rapport 33, 19-22, 1994b.

Wilander, A.: Estimation of Background Sulphate Concentrations in Natural Surface Waters, Water Air Soil Pollut., 75, 371-378, 1994a. 